ACCEPTED MANUSCRIPT

\title{
In-liquid arc plasma jet and its application to phenol degradation
}

To cite this article before publication: Jing-Lin Lin Liu et al 2018 J. Phys. D: Appl. Phys. in press https://doi.org/10.1088/1361-6463/aaada2

\section{Manuscript version: Accepted Manuscript}

Accepted Manuscript is "the version of the article accepted for publication including all changes made as a result of the peer review process, and which may also include the addition to the article by IOP Publishing of a header, an article ID, a cover sheet and/or an 'Accepted

Manuscript' watermark, but excluding any other editing, typesetting or other changes made by IOP Publishing and/or its licensors"

This Accepted Manuscript is @ 2018 IOP Publishing Ltd.

During the embargo period (the 12 month period from the publication of the Version of Record of this article), the Accepted Manuscript is fully protected by copyright and cannot be reused or reposted elsewhere.

As the Version of Record of this article is going to be / has been published on a subscription basis, this Accepted Manuscript is available for reuse under a CC BY-NC-ND 3.0 licence after the 12 month embargo period.

After the embargo period, everyone is permitted to use copy and redistribute this article for non-commercial purposes only, provided that they adhere to all the terms of the licence https://creativecommons.org/licences/by-nc-nd/3.0

Although reasonable endeavours have been taken to obtain all necessary permissions from third parties to include their copyrighted content within this article, their full citation and copyright line may not be present in this Accepted Manuscript version. Before using any content from this article, please refer to the Version of Record on IOPscience once published for full citation and copyright details, as permissions will likely be required. All third party content is fully copyright protected, unless specifically stated otherwise in the figure caption in the Version of Record.

View the article online for updates and enhancements. 


\title{
In-liquid arc plasma jet and its application to phenol degradation
}

\author{
Jing-Lin Liu ${ }^{1}$, Hyun-Woo Park ${ }^{2}$, Ahmad Hamdan ${ }^{3}$, Min Suk Cha* \\ King Abdullah University of Science and Technology (KAUST)
}

Clean Combustion Research Center (CCRC), Physical Science and Engineering Division (PSE),

Thuwal, 23955-6900 Saudi Arabia ${ }^{1}$

E-mail: $\underline{\text { min.cha@ } @ \text { kaust.edu.sa }}$

\begin{abstract}
We present a new method for achieving chemical reactions induced by plasmas with liquidsan in-liquid arc plasma jet system — designed to have a few advantages over the existing methods. High-speed imaging and optical emission spectroscopy were adopted to highlight the physical aspects of the in-liquid arc plasma jet system, and the feasibility of the system was investigated in a wastewater treatment case with phenol as the model contaminant. We found that the specific energy input is a reasonable parameter by which to characterize the overall process. The phenol removal reaction could be modeled as a pseudo-first-order reaction, and the reaction constant became smaller as the phenol concentration increased. However, complete decomposition of the phenol into water and carbon dioxide required very high energy because the final intermediate, oxalic acid, is relatively stable. Detailed chemical and physical analyses, including byproducts, ions, solution acidity, and conductivity, were conducted to evaluate this new method for use in the appropriate applications.
\end{abstract}

Keywords: In-liquid plasma; arc plasma jet; phenol; water purification.

Current addresses ${ }^{1}$ Dalian University of Technology, China, ${ }^{2}$ LG Electronics, Korea, ${ }^{3}$ University of Montreal, Canada 


\section{Introduction}

Plasmas in liquid or in contact with liquids have the potential to be utilized in a wide range of applications, such as wastewater treatment, material synthesis, biomedical applications, and liquid fuel reformation [1-3]. To induce chemical reactions in liquids using plasmas $[4,5]$, those plasmas can be applied via three technical approaches: i) direct electrical discharges in liquids [4]; ii) the introduction of gaseous bubbles to facilitate the direct in-liquid discharges [6]; and iii) the generation of plasmas in a gas layer above the surface of the liquid [7].

Each of these three methods has its own technical values and constraints depending on the application. From a purely physical and chemical point of view, the direct electrical discharges in liquids require very high applied voltage to breakdown the dense liquid medium, and anticipating reactive species generated from the discharge are limited by the liquid contents only. The direct discharges are also sensitive to the physical properties of the liquid, such as electrical conductivity and permittivity. Meanwhile, the plasma generation in a gas above the liquid surface needs moderate applied voltage, producing various reactive species originated from oxygen and nitrogen as well as the contents in the liquid. Because chemical reactions in inter-diffusional zones at a gas-liquid interface are dominant factor for an overall performance, the diffusional and convectional transports of the reactive species and the ratio of the liquid surface to its volume should be potential limiting parameters affecting the efficiency of a process. On the other hand, when gaseous bubbles are introduced into the discharge zone of the direct in-liquid discharges, the discharges are facilitated showing lowered breakdown voltage and enriched reactive species due to the injected gas. Increased reactive volume (bubble-liquid interface) and enhanced mixing caused by the dynamic motions of the bubbles are other feasible merits of the discharges in the bubbled liquid. This method can be thought as a better technical approach to cover the potential limitations of the former two methods. However, the physical properties of the liquid are still influential to the discharges even in the bubbled liquid, such that a discharge optimization should be required for a specific liquid of interest depending on a target application. In this regard, the development of an in-liquid discharge system that addresses each 
weakness listed above may open more opportunities to utilize plasmas in liquids.

Therefore, we developed a system that uses a conventional arc torch to inject a plasma jet into a liquid, which consisted of a DC non-transferred arc plasma jet at the bottom of a liquid-containing reactor (figure 1). It should be highlighted that this proposed method is different from previous studies, which employed arc discharges; arc discharges have been considered in the direct in-liquid discharges or in bubbled liquid discharges, but the present system produces an arc plasma jet remotely and injects it into a treated liquid. We expected to achieve the following improvements via this in-liquid arc plasma jet system: i) an increased plasma-liquid interaction area by supplying plasma bubbles to liquid and ii) a strong UV emission, heat release, and turbulent mixing due to the arc jet may result in augmented efficiency, and iii) a plasma generation is independent of the physical properties of liquid, thus this proposed system is ready to be adopted to any kind of liquid without further modification.

We tested the feasibility of the in-liquid arc plasma jet system in an in-water application; specifically, the degradation characteristics of phenol-contaminated water. Phenol was selected as the test case due to the extensive data available for comparison [3, 8-10]. We analyzed the degradation pathway of phenol and its reaction kinetics to show the technical potential of the in-liquid arc jet system, including the interaction between the plasma, bubbles, and physical parameters of the treated solution, such as conductivity and acidity. We noted that organics in wastewater effluents cause serious environmental and human health problems due to their high chemical oxygen demand (COD), low biodegradability, and toxicity $[11,12]$. Plasma processes, including pulsed discharges [13, 14], dielectric barrier discharges $[11,15,16]$, glow discharges $[17,18]$, and arc discharges $[19,20]$ with or without catalysts and chemical additives, have been investigated to purify wastewater. However, it is difficult to compare the pros and cons among various plasma processes, because overall performances are highly affected by the aforementioned configurations how those plasma sources are coupled with liquids, say direct in-liquid discharges, discharges in a gas over a liquid surface, or discharges in bubbled liquid. 


\section{Experiment}
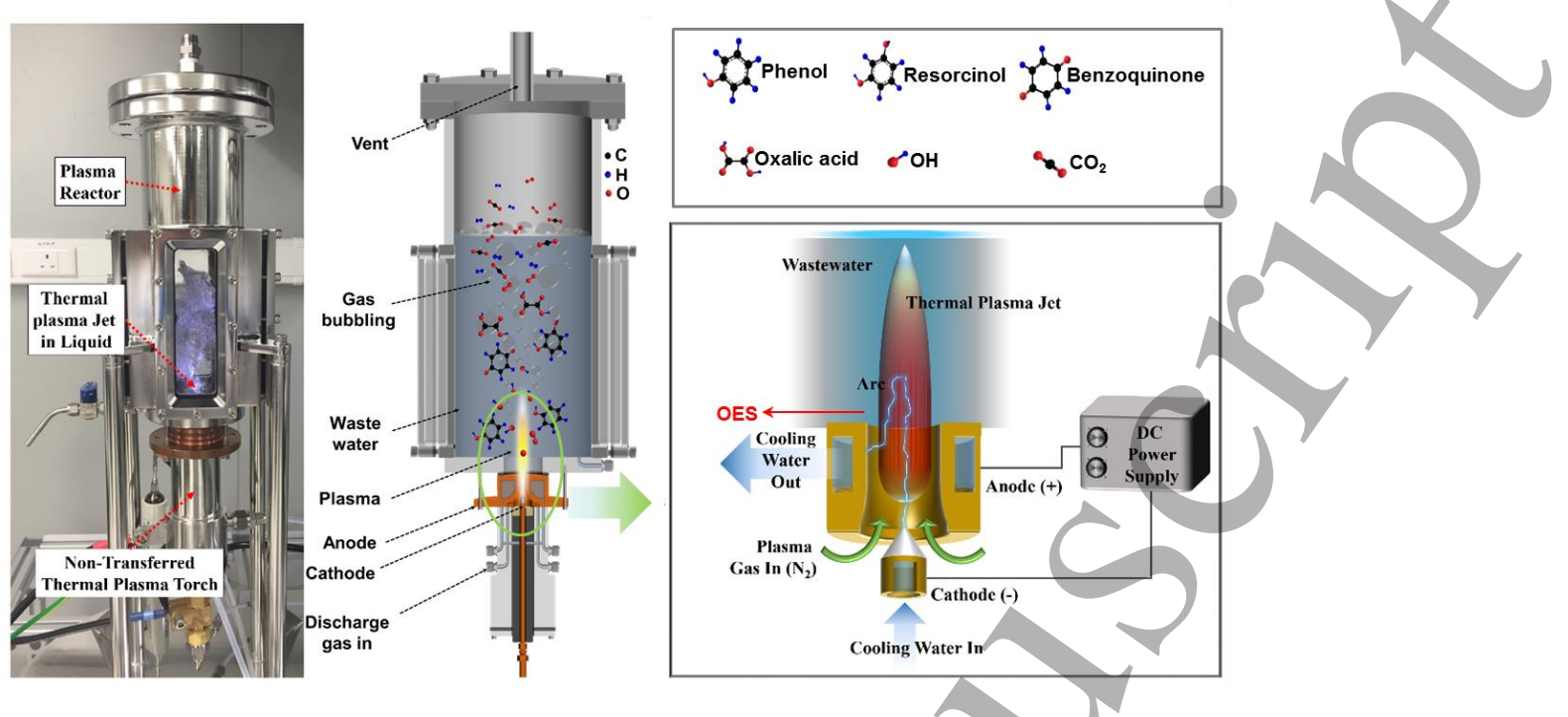

Figure 1. Photo and schematic diagram of the in-liquid arc plasma jet system.

Figure 1 shows a photo and schematic diagram of the in-liquid arc plasma jet system. The system consisted of a DC non-transferred arc plasma torch and a stainless-steel solution container. The arc plasma torch was located at the bottom of the container, and directly injected a plasma jet into the solution. The arc jet was formed by a rotating arc channel, which was generated between a rod-type inner cathode and a cylindrical outer anode with the narrowest inter-electrode gap distance being 2 $\mathrm{mm}$. The nozzle diameter was $3 \mathrm{~mm}$ at the exit. A DC power supply (Perfect 70P, Perfect DAIDAI) with the power fixed at $1.61 \mathrm{~kW}$ was adopted for the arc generation. The discharge power was calculated as the product of average voltage and average current, as measured by a high-voltage probe (P6015A, Tektronix) and a clamp meter (675, AEMC Instruments), respectively, in conjunction with an oscilloscope (MSO 2024B, Tektronix). Circulating, cool water from a chiller (Thermoflex 2500, Thermo Scientific) was supplied to both electrodes in order to consistently maintain the discharge and prolong the lifetime of the electrodes. Nitrogen was selected as the discharge gas and was fed tangentially to the arc torch at $10 \mathrm{~L} / \mathrm{min}$ flow rate.

The stainless-steel container was cylindrical with four quartz windows, an inner diameter of 
$108 \mathrm{~mm}$, and a length of $327 \mathrm{~mm}$. Phenol (Content $\geq 99.5 \%$, Fluka) was selected as the model contaminant and mixed with deionized water. The amount of phenol contained water was varied in a range of $400-1000 \mathrm{~mL}$, and the initial phenol concentration was varied in a range of $50-400 \mathrm{mg} / \mathrm{L}$.

A high-speed camera (LaVision, Image Pro HS) captured the dynamic motion of the bubbles generated by the plasma jets at a frame rate of 1000 fps. A spectrometer (Princeton Instruments, SP2750) equipped with an intensified charge-coupled device (ICCD) camera (Princeton Instrument, PI-MAX3) was used to estimate the temperature of the plasma jet by optical emission spectroscopy (OES).

The chemical components in the plasma-treated wastewater were analyzed using a gas chromatography mass spectrometry/flame ionization detector (GC-MS/FID) (Agilent, 7890A-5975C), with a capillary column (Agilent, DB-5MS). As shown in figure 2, phenol and its byproducts of catechol, resorcinol, and benzoquinone was detected. Oxalate and $\mathrm{NO}_{3}{ }^{-}$in the liquid were measured by ion chromatography (IC) (Dionex, ICS3000) with a column of AS18 and a conductivity detector. A COD photometer (Aqualytic, AL200) measured the chemical oxygen demand (COD) of the plasmatreated wastewater using a potassium dichromate method. A pH sensor (Mettler Toledo, Inlab Expert Go-ISM) and a conductivity meter (Mettler Toledo, Inlab 731-ISM) were used to measure the acidity $(\mathrm{pH})$ and the conductivity, respectively, of the plasma-treated wastewater. Hydrogen peroxide was also measured using a $\mathrm{H}_{2} \mathrm{O}_{2}$ photometer (ProMinent, DULCOTEST-DT3B). Meanwhile, gaseous products were analyzed using on-line gas chromatography thermal conductivity detector (GC/TCD) (Agilent, 7890A) for $\mathrm{O}_{2}$ and $\mathrm{H}_{2}$, and an on-line Fourier transform infrared (FT-IR) spectroscopy (Thermo Scientific, Nicolet iS10) equipped with a 2-m gas cell for $\mathrm{CO}, \mathrm{CO}_{2}, \mathrm{NO}$, and $\mathrm{NO}_{2}$. 


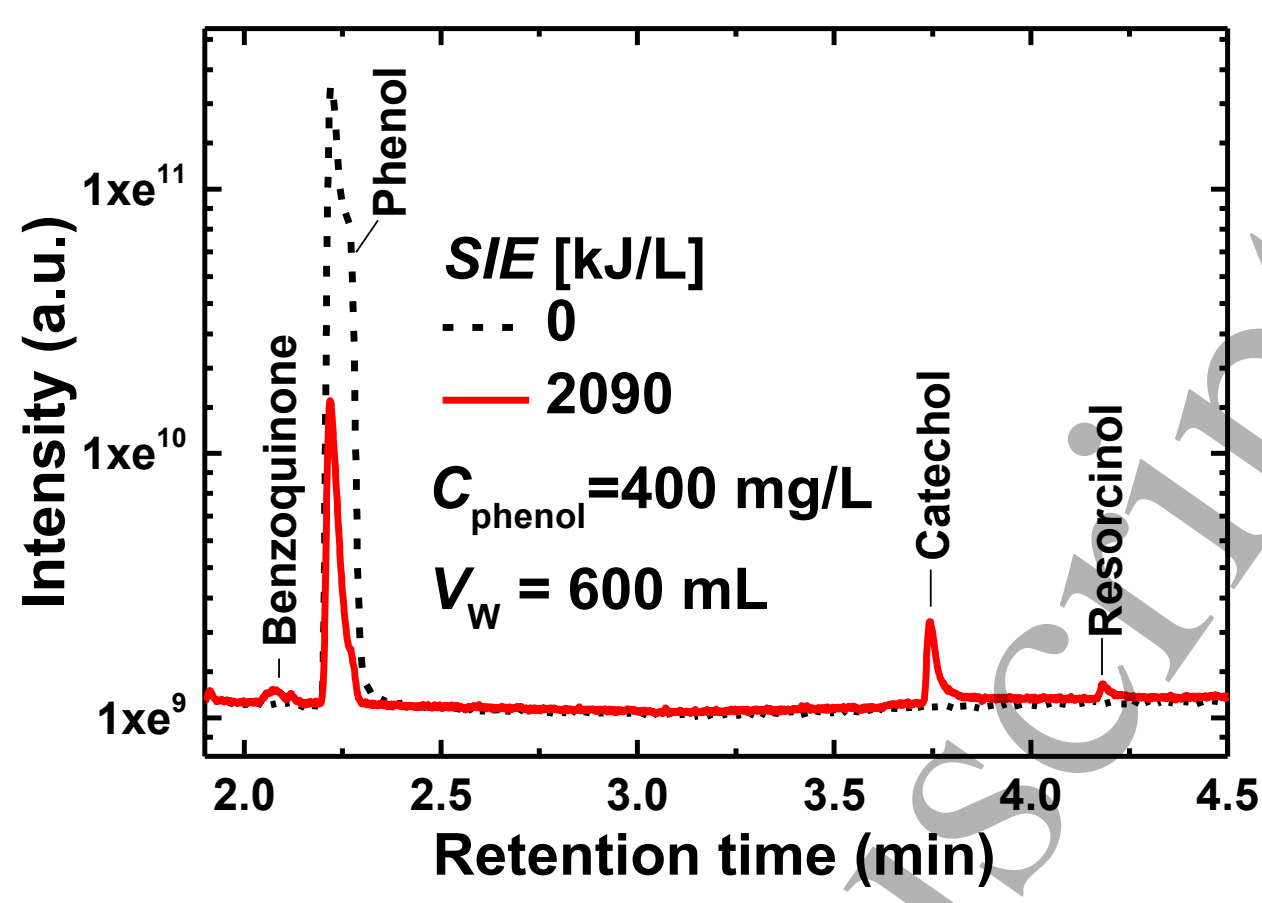

Figure 2. GC-MS spectrum of the treated wastewater with SIE of $2090 \mathrm{~kJ} / \mathrm{L}$, initial phenol concentration of $400 \mathrm{mg} / \mathrm{L}$ and wastewater volume of $600 \mathrm{~mL} . S I E=0$ represents the untreated initial spectrum for comparison.

To characterize the phenol degradation, we defined the degradation efficiency $\left(\eta_{\text {phenol }}\right)$ and the COD removal efficiency $\left(\eta_{\mathrm{COD}}\right)$ respectively a

$$
\begin{aligned}
& \text { phenol }(\%)=\frac{\left(C_{\text {phenol }}\right)_{0} \quad\left(C_{\text {phenol }}\right)_{S I E}}{\left(C_{\text {phenol }}\right)_{0}} 100, \\
& \operatorname{COD}(\%)=\frac{\mathrm{COD}_{0} \mathrm{COD}_{S I E}}{\mathrm{COD}_{0}} 100,
\end{aligned}
$$

where $C_{\text {phenol }}$ is the concentration of phenol, and the subscripts zero and SIE denote the initial condition and the treated condition at a given specific input energy (SIE), respectively. SIE was defined as

$$
S I E(k J / L)=\frac{P_{i n} \cdot t_{p}}{V_{w}},
$$


where $P_{i n}$ is the discharge power, $t_{p}$ is the plasma processing time, and $V_{w}$ is the volume of the treated wastewater.

\section{Results and discussion}

\subsection{Physical and chemical characterization of the arc plasma jet}

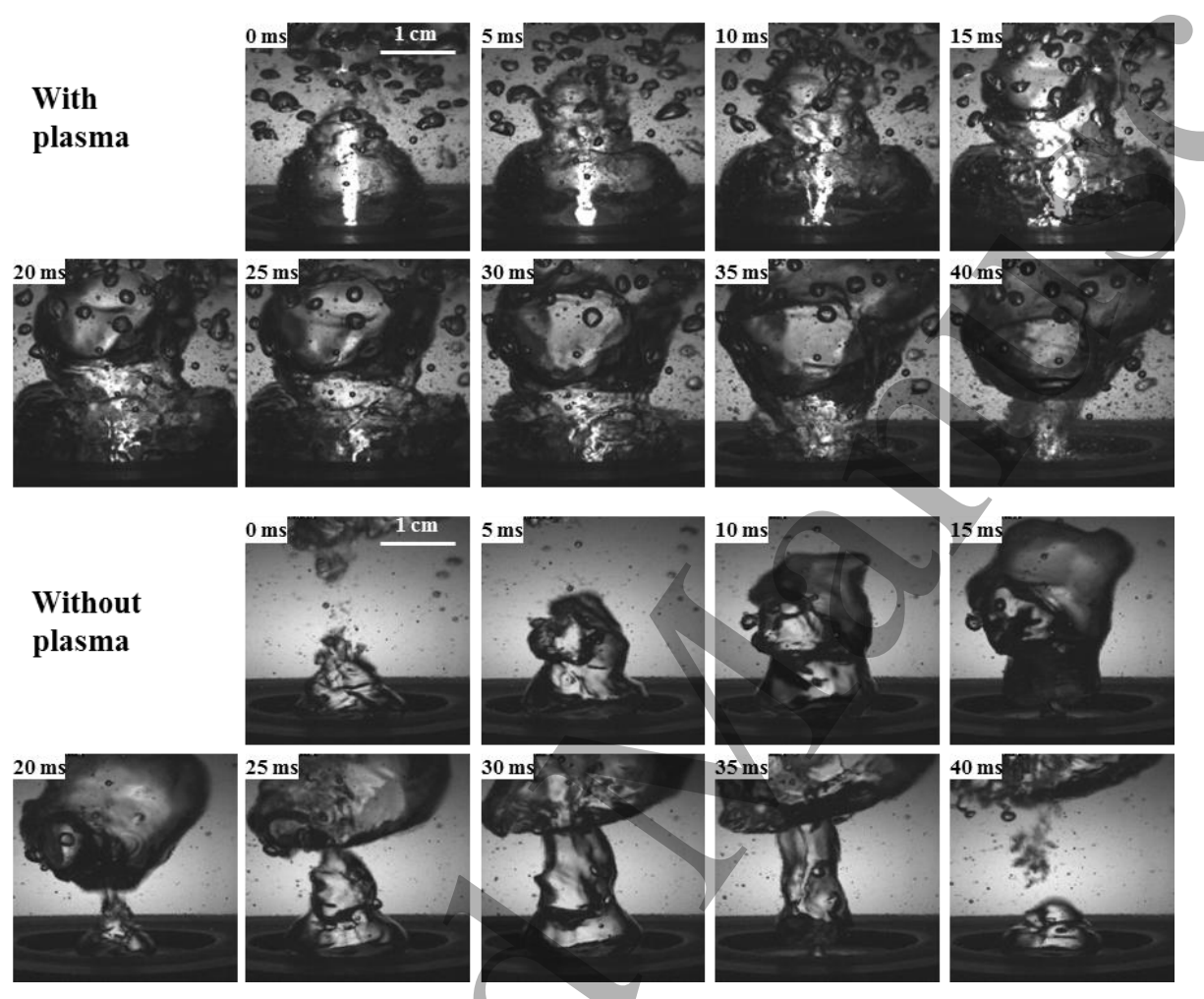

Figure 3. High-speed images of gas bubbles with and without plasma.

First, we investigated the dynamic behavior of the arc plasma jet in water using the high-speed camera. The results are presented in figure 3 (see also Supplementary Movie 1) alongside the bubble motion from a simple, cold nitrogen jet without plasma for comparison (see also Supplementary Movie 2); both have a flow rate of $10 \mathrm{~L} / \mathrm{min}$. The size of the main bubble and the shedding frequency should be dependent on buoyancy and surface tension, which are affected by the physical properties of fluids, nozzle size, and gas jet velocity.

For the nitrogen jet without plasma, a rather large bubble $(\sim 2 \mathrm{~cm})$ intermittently detached at 
intervals of $\sim 40 \mathrm{~ms}$. At $20-35 \mathrm{~ms}$, a thin gaseous column shrank radially below the main bubble originating at the nozzle, before the main bubble finally detached. However, when the arc plasma was ignited at the same flow rate as the nitrogen, we found a very dynamic interaction between the plasma zone and the water (see the bright emission in the center of the gas bubble in figure 3). At $40 \mathrm{~ms}$, for example, the reduced radial size of the gaseous column led to a direct interaction between the hot plasma zone and the water surface. This resulted in a sudden expansion of the column, which we attribute to significant water evaporation at the interface. This behavior can be clearly seen in Supplementary Movie 1.

The thermal and electron impact reactions from the introduction of water vapor to the reactive plasma zone was the seed of many reactive species, such as $\mathrm{OH}, \mathrm{O}$, and $\mathrm{H}$. Thus, the direct influence of the arc plasma jet on the interface between the plasma and the liquid, and the augmented transport of water vapor to the gas stream due to robust heating, are very important features of the proposed plasma jet system.

The gas expansion and water evaporation caused by the high temperature of the plasma arc played a positive role in the mixing characteristics due to the pure fluid dynamic effect. The sudden expansion of the gaseous column caused by the direct impact of the plasma zone on the plasma-liquid interface created many small, millimeter- and micrometer-sized bubbles (figure 3), indicating a significantly increased reaction area. We note that the periodically pulsating motion of the column expansion also contributed to the mixing characteristics. A higher gas velocity-roughly 10 times higher than the cold, pure nitrogen jet when the plasma temperature is around $3000 \mathrm{~K}$-facilitated turbulent mixing between the two phases.

Strong ultraviolet (UV) radiation and a thermal effect at the interface from the high-temperature plasma arc could also facilitate UV sterilization and thermal degradation, for example, depending on a target application of the plasma jet system. 


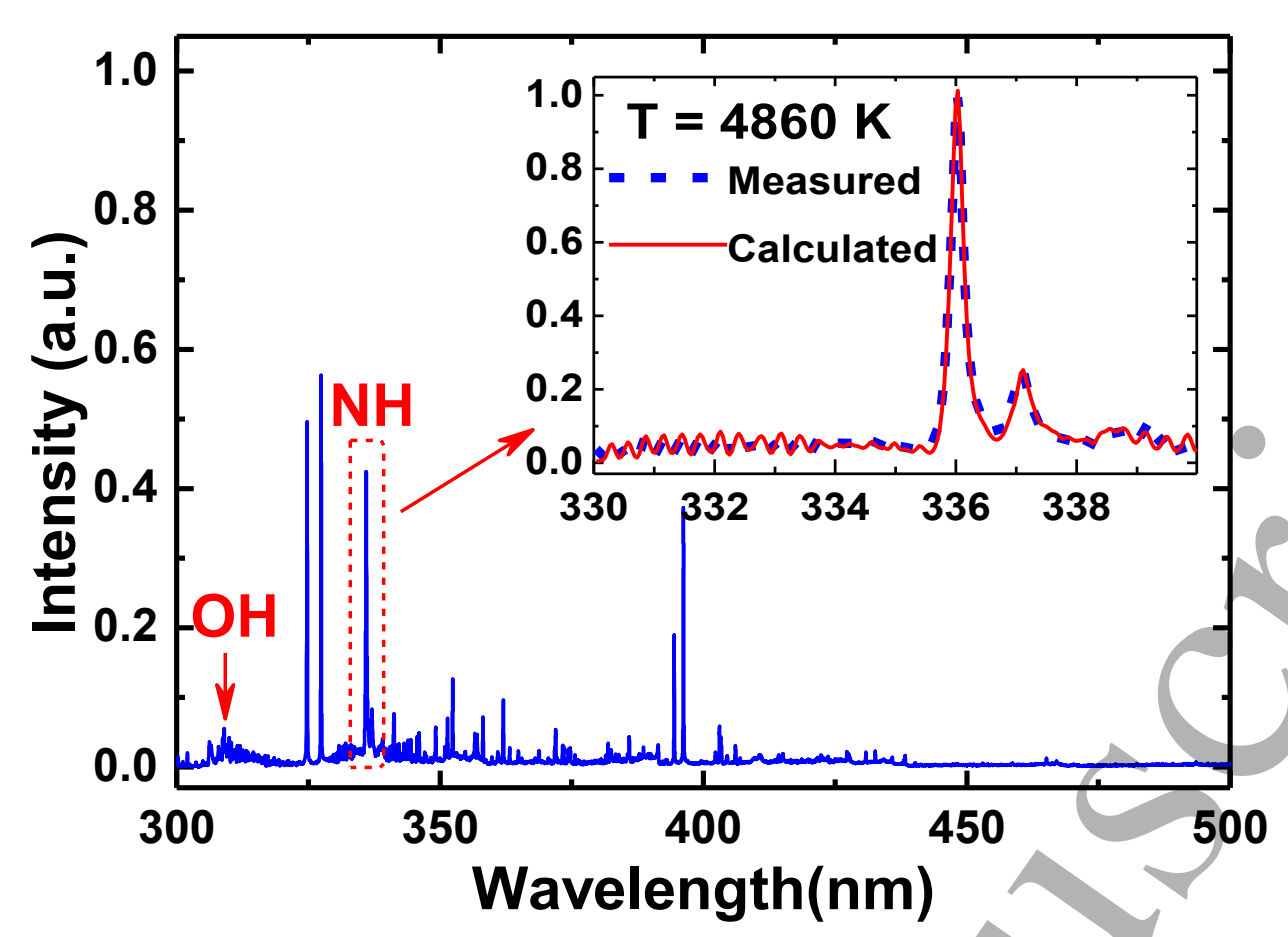

Figure 4. Spectral lines from optical emission spectroscopy and the estimation of rotational temperature using $\mathrm{NH}$ emission lines.

To investigate which species were generated by the in-water arc plasma jet system, we conducted OES; the results are presented in figure 4. Hydroxyl radicals, NH, and a series of copper lines were observed. Therefore, we conclude that the direct influence of the plasma jet on the interface and water vapor in the plasma zone facilitated the production of chemically reactive species that oxidized the organic components. Copper emission lines due to the erosion of the electrode material were also visible near the $\mathrm{OH}$ emission band at $\sim 310 \mathrm{~nm}$, which prevented the gas temperature from being estimated using the $\mathrm{OH}$ lines. For this reason, we used the $\mathrm{NH}$ emission lines captured horizontally near the root of the plasma jet ( $1 \mathrm{~mm}$ above the nozzle tip) to estimate the rotational temperature $(\sim 4860 \mathrm{~K})$, which should reasonably reflect the average gas temperature. The water temperature in the wastewater container was directly measured as $353 \mathrm{~K}$ by a thermocouple at $S I E=$ $3700 \mathrm{~kJ} / \mathrm{L}\left(P_{\text {in }}=1.61 \mathrm{~kW}, V_{\mathrm{w}}=600 \mathrm{~mL}\right.$, and $\left.t_{p}=23 \mathrm{~min}\right)$. Therefore, the estimated temperature range in the wastewater container was 353-4860 K.

To determine the chemical aspect of the arc plasma jet caused by temperature, exclusive of the 
electron-impact reactions, we calculated the thermodynamic equilibrium composition for various temperatures within the range $300-5000 \mathrm{~K}$ using a Gibbs energy minimization routine in MatLab. It should be noted that the equilibrium calculation cannot precisely capture the effects of the plasma on the related chemical reaction. However, this approach allows us to take a glimpse of a feasible set of reactive species caused by thermal dissociations.

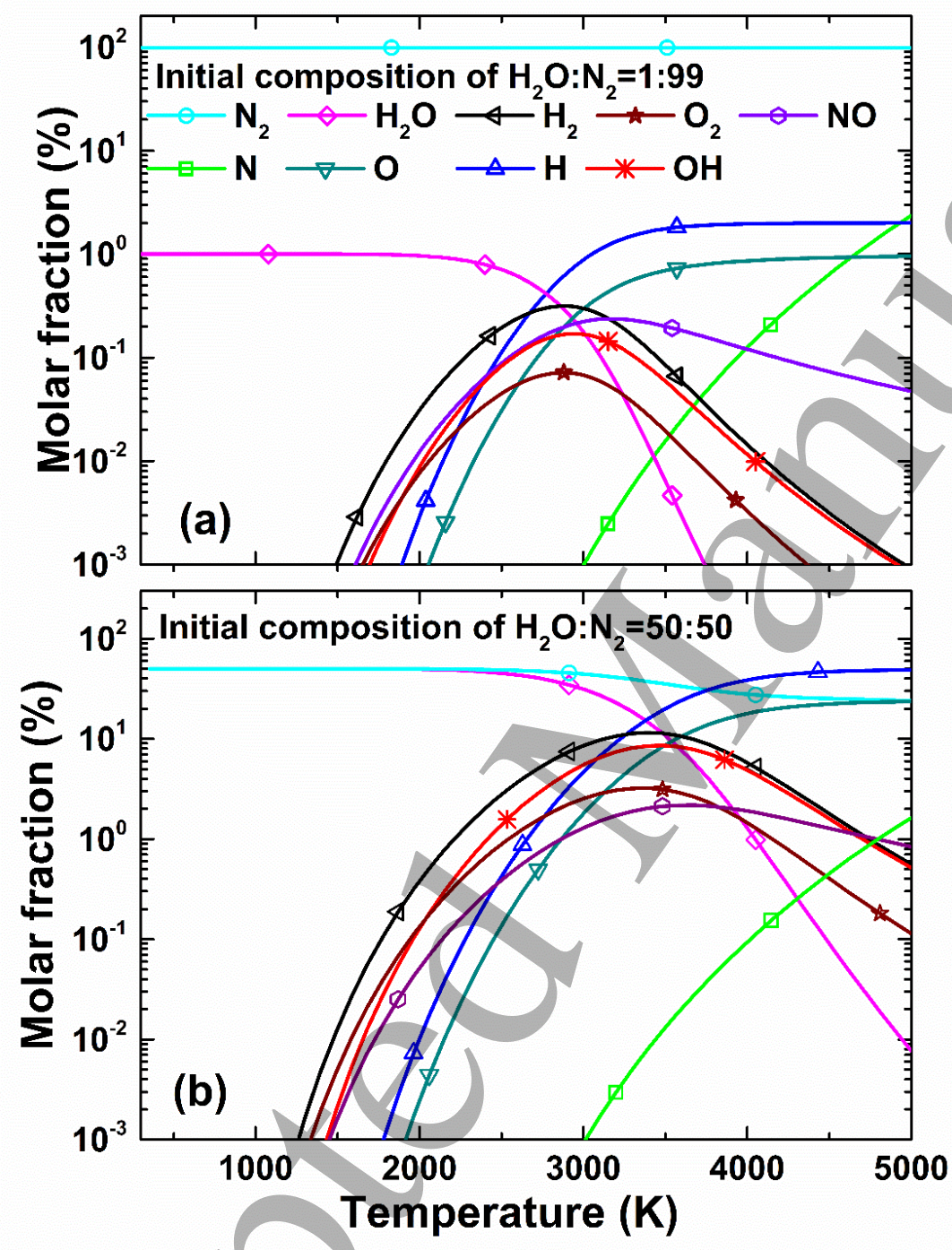

Figure 5. Thermodynamic equilibrium calculation with an initial gas composition of $\mathrm{H}_{2} \mathrm{O}: \mathrm{N}_{2}$ $=1: 99$ (a) and 1:1 (b).

The equilibrium chemical compositions at a range of temperatures for an initial gas composition of $\mathrm{H}_{2} \mathrm{O}: \mathrm{N}_{2}=1: 99$ are illustrated in figure 5a. We found that the thermal dissociation of water started to occur at $\sim 1500 \mathrm{~K}$, producing $\mathrm{H}_{2}, \mathrm{O}_{2}, \mathrm{NO}$, and $\mathrm{OH} ; \mathrm{H}$ and $\mathrm{O}$ radical production followed 
at $\sim 2000 \mathrm{~K}$. A significant quantity of $\mathrm{OH}$ radicals was produced in the $2000-4000 \mathrm{~K}$ range, with the peak concentration at $\sim 3000 \mathrm{~K}$. This implies that the arc jet could provide a thermodynamically favorable condition for forming radicals. The partial pressure of superheated water vapor caused the mole fraction of water vapor to reach the order of 10 percent at $>373 \mathrm{~K}$. An extreme example with $\mathrm{H}_{2} \mathrm{O}: \mathrm{N}_{2}=1: 1$ is shown in figure $5 \mathrm{~b}$. There was no significant change in the overall trends; increased concentrations of water resulted in higher concentrations of the reactive species.

Even without considering the electron-impact reactions, we found that the $\mathrm{OH}$ radicals, which efficiently oxidize organic pollutants in solutions [3], are a major reactive species in the present system, and their production pathways directly result from the dissociation of water, as $\mathrm{H}_{2} \mathrm{O}+\mathrm{N}_{2} \rightarrow \mathrm{OH}+\mathrm{H}$ $+\mathrm{N}_{2}$, and other radical propagation reactions, as $\mathrm{H}_{2} \mathrm{O}+\mathrm{H} \rightarrow \mathrm{H}_{2}+\mathrm{OH}$ and $\mathrm{H}_{2} \mathrm{O}+\mathrm{O} \rightarrow 2 \mathrm{OH}$. No hydrogen peroxide $\left(\mathrm{H}_{2} \mathrm{O}_{2}\right)$ was predicted in the simulation, which should be attributed to the following reactions with $\mathrm{NO}$ and $\mathrm{NO}_{2}$, respectively:

$$
\begin{aligned}
& \mathrm{H}_{2} \mathrm{O}_{2}+\mathrm{NO} \rightarrow \mathrm{OH}+\mathrm{HNO}_{2} \\
& \mathrm{H}_{2} \mathrm{O}_{2}+\mathrm{NO}_{2} \rightarrow \mathrm{OH}+\mathrm{HNO}_{3},
\end{aligned}
$$

The reactions in (4) and (5) actually enhanced the $\mathrm{OH}$ radical concentrations. This point will be further discussed in the next Section.

\subsection{Phenol degradation characteristics}

We conducted phenol degradation experiments, expecting that the aforementioned physical and chemical aspects of the in-liquid arc plasma jet system should facilitate the removal of the organic contaminant. We maintained the discharge power throughout the experiment at $P_{\text {in }}=1.61 \mathrm{~kW}$, in order to test the plasma processing time, the volume of phenol containing wastewater, and the initial concentration of phenol. 

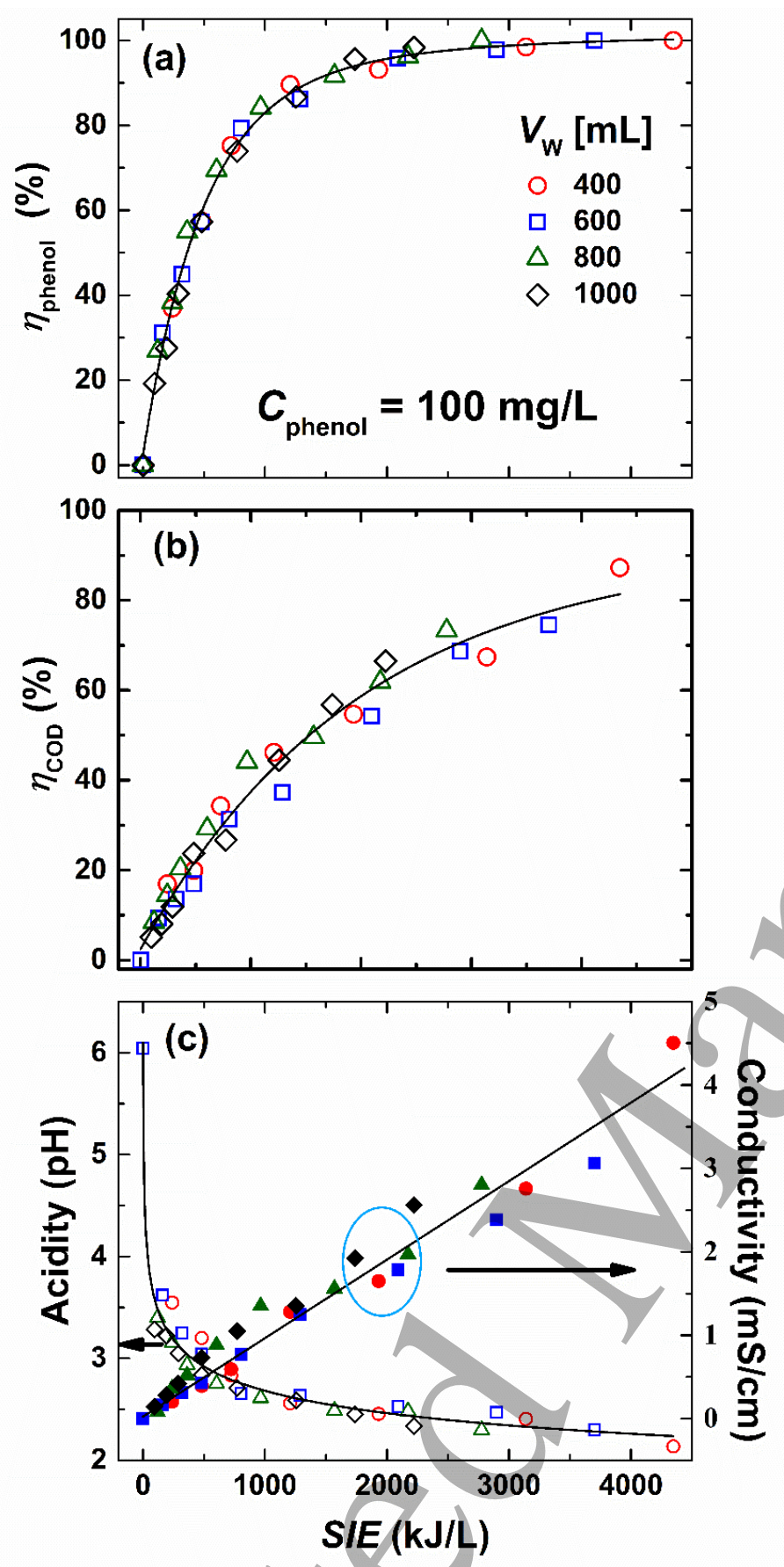

Figure 6. Effect of SIE on (a) phenol degradation efficiency, (b) COD removal efficiency, and (c) acidity $(\mathrm{pH})$ and conductivity at various wastewater volumes.

In our first experiment, we fixed the initial concentration of phenol at $100 \mathrm{mg} / \mathrm{L}$, while varying the amount of wastewater and the processing time independently. Figure 6 illustrates the efficiency of (a) phenol degradation ( $\left.\eta_{\text {phenol }}\right)$ and (b) COD removal ( $\left.\eta_{\mathrm{COD}}\right)$, and (c) the acidity and conductivity of the solution. Most importantly, we found that the phenol degradation efficiency, COD removal 
efficiency, and solution acidity and conductivity were characterized only by SIE at the fixed initial phenol concentration, regardless of the plasma processing time and the total amount of treated wastewater, indicating that SIE is the sole parameter controlling the overall performance. As SIE increased, the phenol degradation first increased rapidly to $\sim 90 \%$ at $S I E=1000 \mathrm{~kJ} / \mathrm{L}$, then slowed to show asymptotic behavior as it approached $100 \%$.

However, the corresponding COD removal only reached $\sim 40 \%$ at $S I E=1000 \mathrm{~kJ} / \mathrm{L}$, implyíng that there were organic byproducts remaining in the treated wastewater. Even at $S I E=4800 \mathrm{~kJ} / \mathrm{L}$, the COD removal efficiency was only $\sim 80-90 \%$. Thus, a significantly higher SIE would be required to fully mineralize the organic byproducts.

The solution acidity and conductivity were significantly affected by SIE. The conductivity increased linearly with $S I E$, whereas the acidity dropped rapidly and showed asymptotic behavior. We attribute this to the formation of nitric acids in the treated solution, and will discuss it later in this section. Although bubbled in-liquid discharges usually show deteriorating discharge probability with increased conductivity [21], the present arc plasma jet was not affected by changes in acidity or conductivity. This suggests that this method could be applied in any liquid, regardless of its physical properties. 

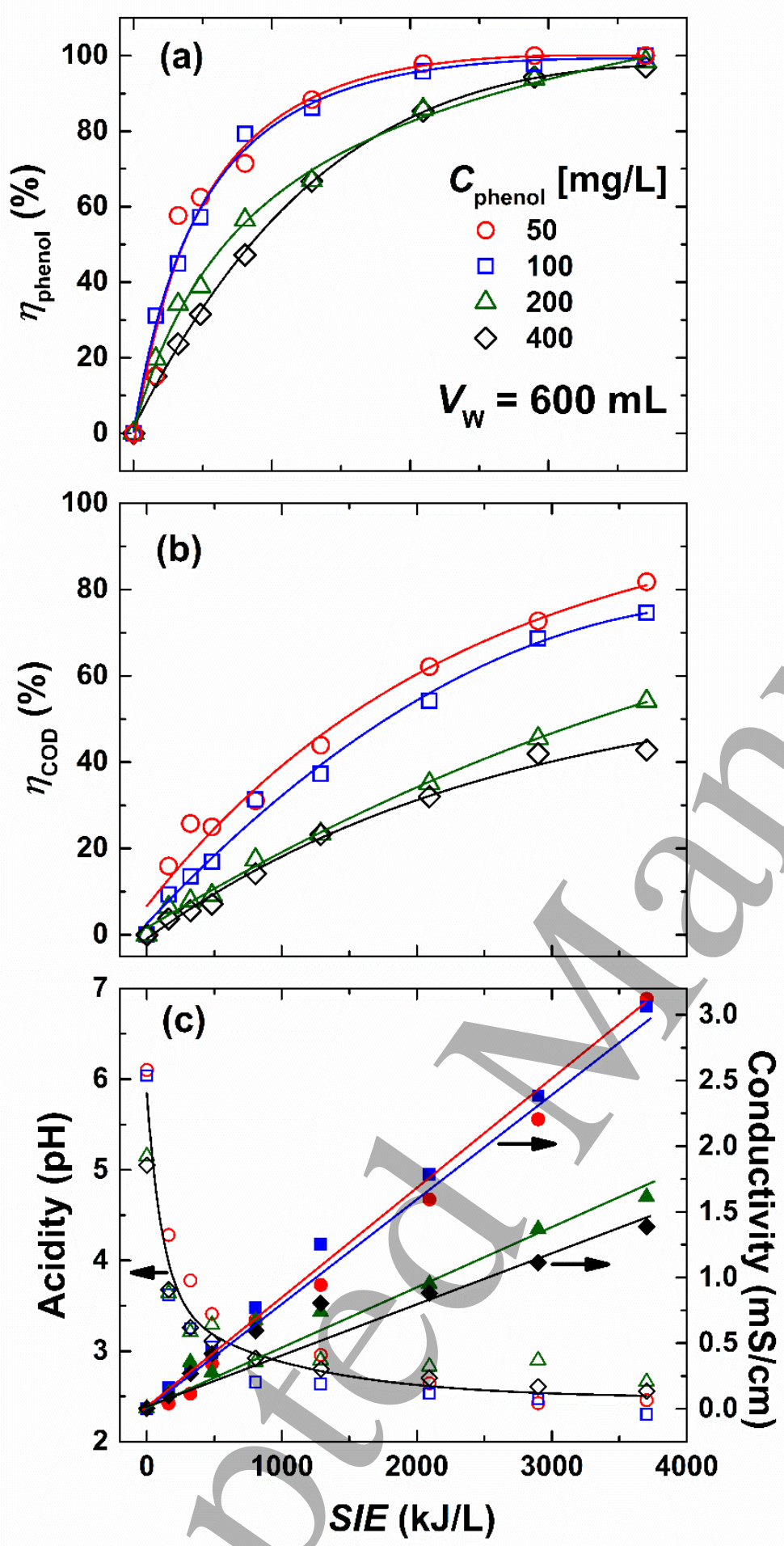

Figure 7. Effect of SIE on (a) phenol degradation efficiency, (b) COD removal efficiency, and (c) acidity $(\mathrm{pH})$ and conductivity at various initial phenol concentrations.

In order to understand the important role of SIE on phenol degradation, we conducted the same 
experiment for various initial phenol concentrations at a fixed $V_{\mathrm{w}}=600 \mathrm{~mL}$ and $P_{\text {in }}=1.61 \mathrm{~kW}$. In general, the phenol degradation efficiency (figure 7a) and the COD removal efficiency (figure 7b) reflected that a higher SIE was required to effectively remove the phenol and its intermediate organic byproducts, i.e., to treat wastewater contaminated with high concentrations of phenol. Because the phenol degradation efficiency, the COD removal efficiency, and the conductivity became insensitive as the initial concentration of phenol increased, demonstrating only small changes between 200 and $400 \mathrm{mg} / \mathrm{L}$, the concentrations of reactive species produced by the arc plasma jet seemed to limit the overall decomposition process. However, we found that with $S I E>3700 \mathrm{~kJ} / \mathrm{L}$, we could achieve almost $100 \%$ phenol removal for all tested initial concentrations of phenol.

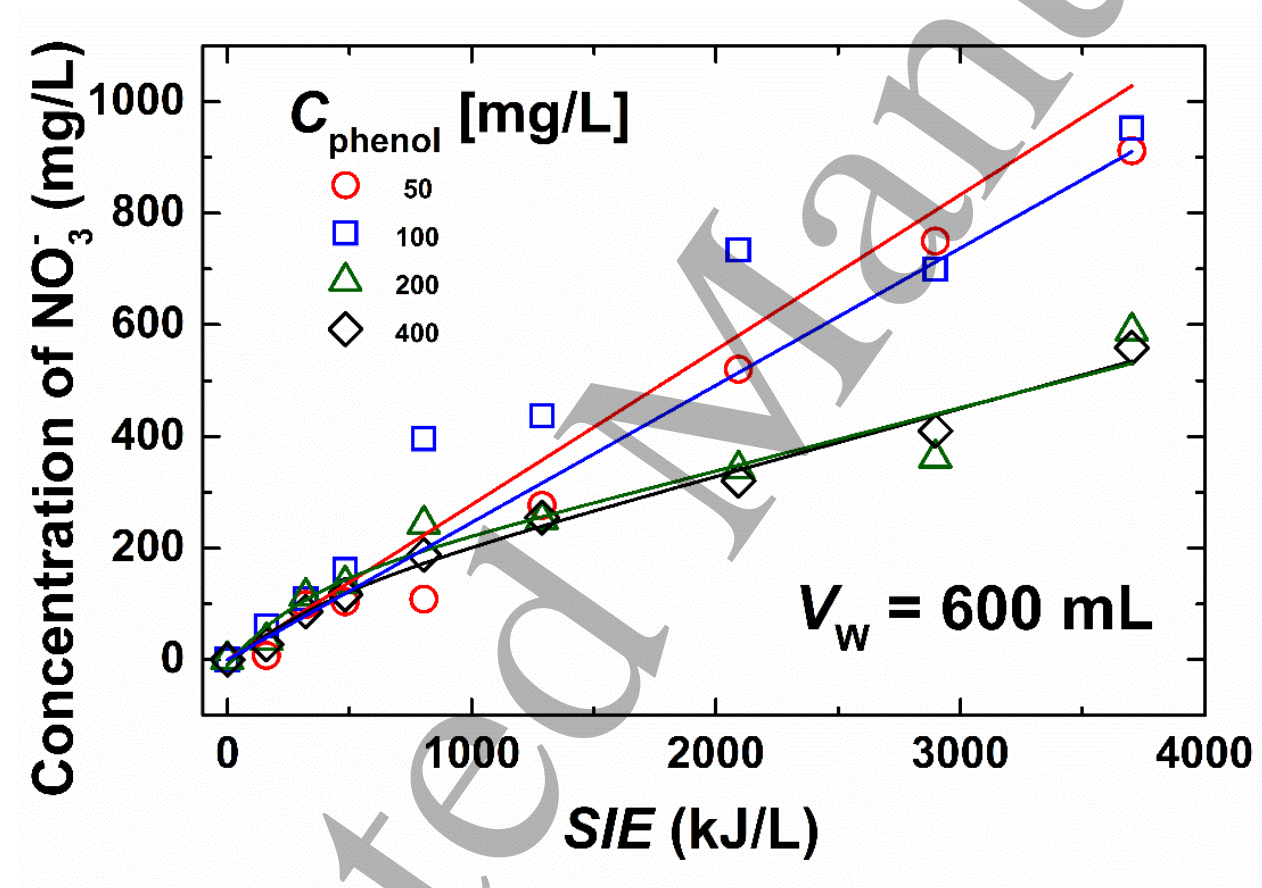

Figure 8. $\mathrm{NO}_{3}$ - concentration in solution versus $S I E$ at various initial phenol concentrations.

To identify the reasons for the decreased $\mathrm{pH}$ and increased conductivity, including dependence on the initial phenol concentration, we measured the ions in the treated liquid sample using IC. We found that $\mathrm{NO}_{3}{ }^{-}$and oxalate were the only ionic species in the treated solution, and the concentration of $\mathrm{NO}_{3}{ }^{-}$was much higher than that of oxalate. $\mathrm{The}^{-} \mathrm{NO}_{3}{ }^{-}$trends at various initial phenol concentrations 
reflected the conductivity trends, as shown in figure 8 .

In general, the $\mathrm{HNO}_{2}$ generated in Eq. (4) was unstable and tended to form $\mathrm{HNO}_{3}$ in the solution, especially in the presence of $\mathrm{OH}$ and $\mathrm{O}$, resulting in an increased concentration of $\mathrm{NO}_{3}{ }^{-}$in the solution. More $\mathrm{OH}$ and $\mathrm{O}$ radicals were required to oxidize this increased initial phenol concentration and its organic byproducts, which resulted in a limited pool of $\mathrm{OH}$ and $\mathrm{O}$ radicals for the conversion of $\mathrm{HNO}_{2}$ into $\mathrm{HNO}_{3}$. Thus, the reduced concentration of $\mathrm{NO}_{3}{ }^{-}$and the consequent reduction in conductivity (due to the increased initial phenol concentration) shown in figure 8 and 7c, respectively, can be reasonably understood.

We also tested the phenol degradation by replacing nitrogen as the discharge gas with argon. Hydrogen peroxide found in the argon arc plasma jet showed increased concentrations with increased SIE; the solution acidity and conductivity were not affected by SIE. However, the phenol degradation efficiency was very low compared to the efficiency achieved when using nitrogen as the discharge gas at similar SIE. This evidenced that the increased concentration of $\mathrm{OH}$ radicals, due to $\mathrm{H}_{2} \mathrm{O}_{2}$ conversion via Eq. (4) reacting with NO in the nitrogen plasma jet, resulted in a better phenol degradation than that from the argon plasma jet. The formation of nitric acids probably caused the solution's acidity and conductivity.

\subsection{Overall reaction of phenol degradation}

We estimated the overall reaction rate of the phenol degradation $(R)$ by introducing a reaction constant $(k)$, and the concentrations of reactive species produced by the plasma jet $\left(C_{\mathrm{RS}}\right)$ and phenol $\left(C_{\text {Phenol }):}\right.$

$$
R=k \cdot C_{\mathrm{RS}} \cdot C_{\text {phenol }} \text {. }
$$

With plasma, the production rate of the reactive species was generally linearly proportional to the discharge power for a given plasma system. Thus, the concentration of the reactive species can be 
described as

$$
C_{\mathrm{RS}}=\frac{A}{V_{\mathrm{W}}} \cdot P_{i n}-\sum k_{i} \cdot C_{\mathrm{RS}} \cdot C_{i}
$$

$$
C_{\mathrm{RS}}=\frac{A}{1+\sum k_{i} \cdot C_{i}} \cdot \frac{P_{i n}}{V_{W}}
$$

Here, $A$ is a constant indicating the amount of produced reactive species per unit power, and $k_{\mathrm{i}}$ and $C_{i}$ are the reaction constant and the concentration of all species that can react with the reactive species, respectively; the first term represents production, and the latter represents consumption of the reactive species. The steady state approximation for the reactive species $\left(C_{\mathrm{RS}}=\right.$ constant $)$ may lead to

By inserting Eq. (8) into Eq. (6), the overall reaction rate at time $t$ is expressed as

$$
(R)_{t}=\frac{d\left(C_{\text {phenol }}\right)_{t}}{d t}=k\left(\frac{A}{1+\sum k_{i} C_{i}} \frac{P_{\text {in }}}{V_{w}}\right) \cdot\left(C_{\text {phenol }}\right)_{t}
$$

By rearranging and then integrating Eq. (9), we have

$$
\ln \left\{\frac{\left(C_{\text {phenol }}\right)_{t}}{\left(C_{\text {phenol }}\right)_{0}}\right\}=k\left(\frac{A}{1+\sum k_{i} C_{i}}\right)\left(\frac{P_{i n} \cdot t}{V_{w}}\right)=k_{p} \cdot S I E
$$

where

$$
k_{p}=k\left(\frac{A}{1+\sum k_{i} C_{i}}\right)
$$

indicating a pseudo-first-order reaction of the phenol degradation. Here, $k_{\mathrm{p}}$ is obtained by plotting the instantaneoûs phenol concentrations according to Eq. (10), as shown in figure 9. The phenol 
degradation reaction showed a pseudo-first-order characteristic, and the experimentally estimated values of $k_{\mathrm{p}}$ decreased from $1.79 \times 10^{-3}$ to $0.95 \times 10^{-3} \mathrm{~L} / \mathrm{kJ}$ as the initial phenol concentration increased from 50 to $400 \mathrm{mg} / \mathrm{L}$. This decrease in $k_{\mathrm{p}}$ is attributed to the increase in $\sum k_{i} \cdot C_{i}$ caused by increased initial phenol concentrations. The pseudo-first-order reaction also implies that the reactive species produced from the in-liquid arc plasma jet were in their steady state for the plotted range of SIE, whereas the acidity and conductivity of the solution had an insignificant impact on both the plasma generation and the phenol degradation.

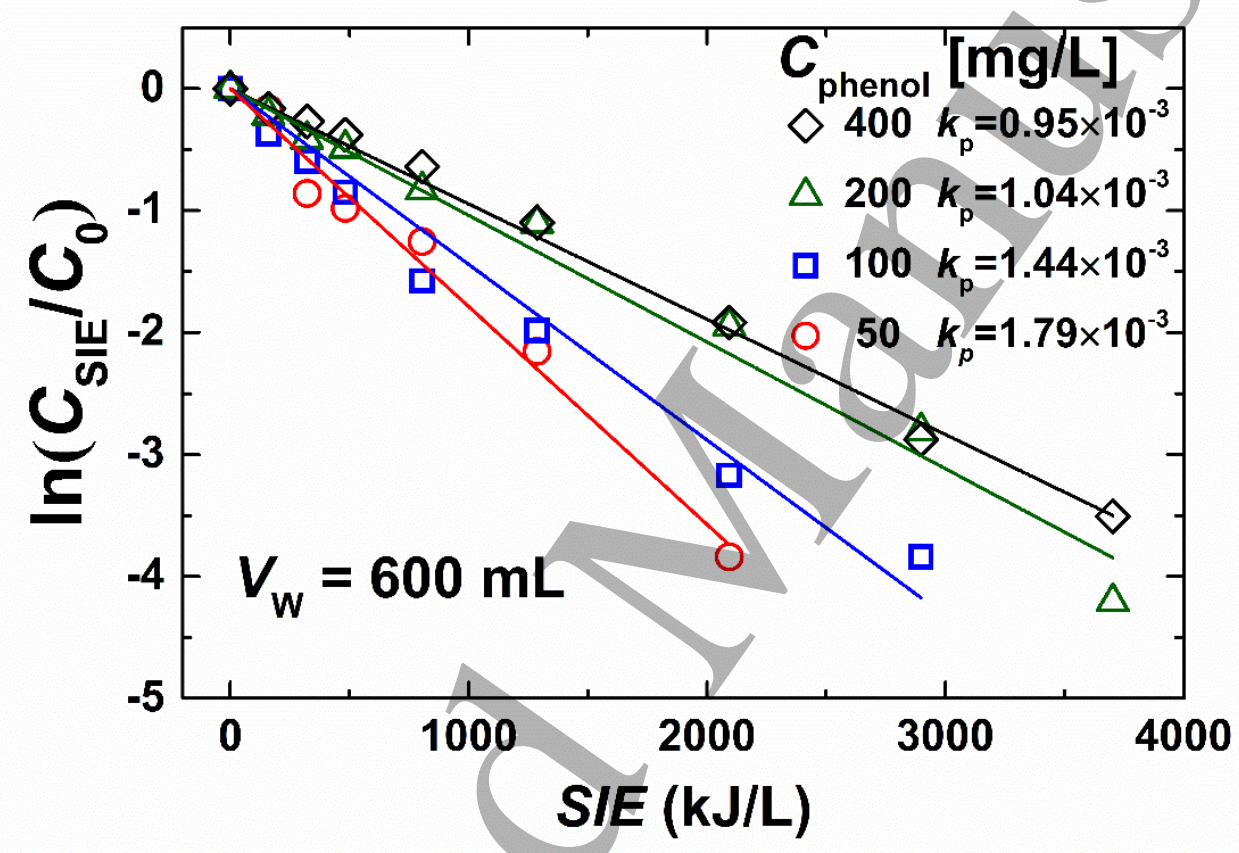

Figure 9. Kinetic plots of phenol degradation at various initial phenol concentrations.

\subsection{Byproducts of phenol degradation and pathways to a complete decomposition}



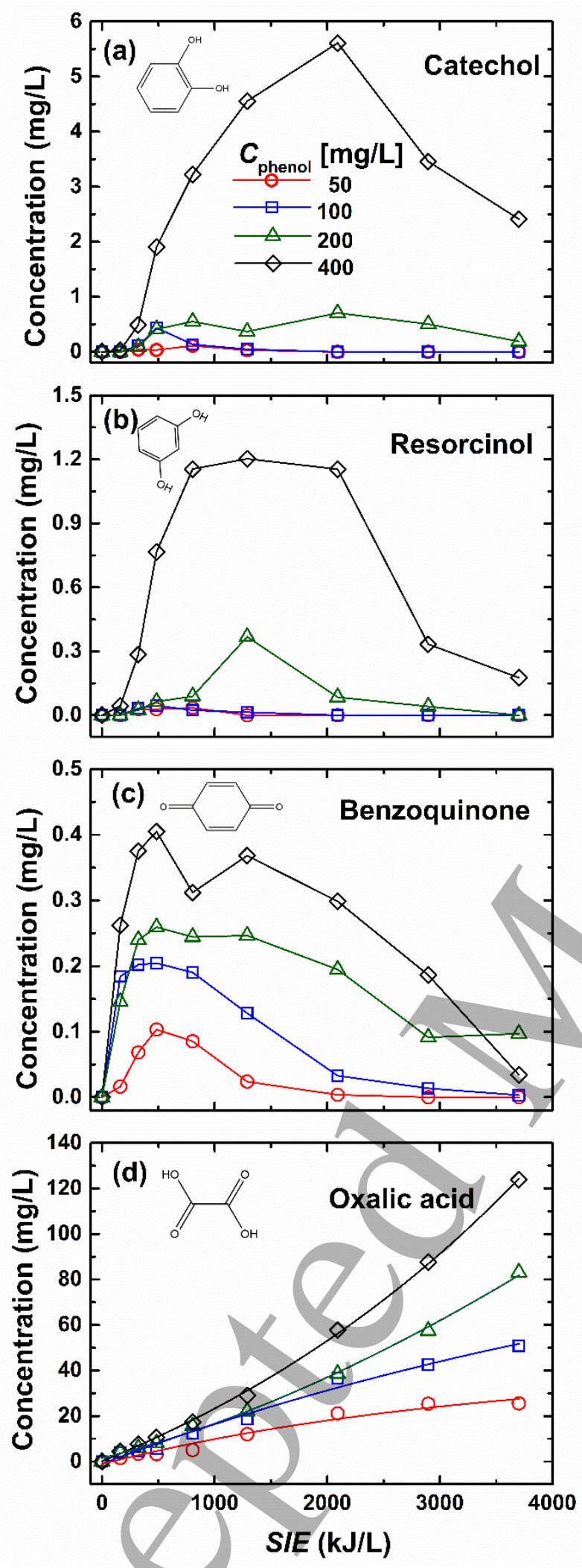

Figure 10. By-products concentrations in liquid versus SIE at various phenol concentrations.

To further clarify the complete decomposition pathway of phenol in the in-liquid arc plasma jet, we analyzed the byproducts of various initial phenol concentrations. Figure 10 illustrates the results 
for organic compounds such as catechol, resorcinol, and benzoquinone, which were measured by the GC-MS/FID, and oxalic acid, which was measured by IC. We identified these four as the major byproducts originating from the phenol in the plasma-treated solution. Note that these byproducts are known to be the most feasible intermediates during a phenol degradation [21]. Although a trace amount of dinitrobenzene was found in the solution with an initial phenol concentration of $400 \mathrm{mg} / \mathrm{L}$, we did not include its data due to difficulties in the quantification limit.

There are many chemical routes by which catechol (figure 10a) and resorcinol (figure 10b) could be produced from phenol during the first step of the degradation in the in-liquid arc plasma jet system . Some feasible pathways include reactions of phenol (or hyroxyphenyl and phenolate) with $\mathrm{H}_{2} \mathrm{O}_{2}, \mathrm{OH}$, and $\mathrm{O}$; the $\mathrm{OH}$ reaction with a phenol molecule in particular prefers to react at the orthoand para-position [22]. These catechol and resorcinol seemed to be further oxidized to benzoquinone (figure 10c), but we were unable to explain the appearance of benzoquinone because it is usually produced from hydroquinone, which was not detected in the present experiment. Then, the ringcleavage reactions of benzoquinone due to $\mathrm{OH}$ should lead to oxalic acid (figure 10d), which was only one kind of the detected ring-cleavage products. Finally, the oxalic acid would be fully oxided directly into $\mathrm{CO}_{2}$ and $\mathrm{H}_{2} \mathrm{O}$, which was partly evidenced by the gaseous component measured by GC. No $\mathrm{CO}$ was detected in the exhaust gas.

As the initial phenol concentration increased, higher concentrations of each byproduct were observed at similar SIE, as shown in figure 10. The concentrations of catechol, resorcinol, and benzoquinone first increased with increased SIE, due to the phenol supply acting as the feedstock of these intermediates. Past a certain SIE, the decomposition rate of phenol decreased because not much phenol was left to be converted; thus, the byproduct concentrations peaked at a certain SIE before decreasing to zero as SIE increased. However, the concentration of oxalic acid was much higher than the other byproducts, indicating that the decomposition process of oxalic acid was the slowest and that it controlled the overall reaction rate of complete decomposition. We found that its concentration continued to increase with SIE, implying that a significantly higher SIE would be required to 
completely decompose the phenol (meaning COD $\sim 0$ ).

\section{Conclusions}

We developed an in-liquid arc plasma jet system to facilitate a certain practical direction of related researches, and we successfully investigated the feasibility of this concept by treating wastewater contaminated by phenol using nitrogen as the discharge gas for the arc plasma jet. Anticipated advantages of using this method were i) an increased reactive plasma-liquid interfacial area by supplying plasma bubbles to liquid; ii) a coherent and independent generation of plasma, irrespective of the liquid's physical properties; and iii) the positive influences of strong UV emission, heat release, and turbulent mixing from the arc plasma jet, depending on the target process.

Using high-speed imaging, we found an enhanced interaction of the plasma zone with water, including an increased population of gaseous bubbles caused by the pulsating and turbulent motion of the plasma jet. Major reactive species produced in the system were identified as $\mathrm{OH}, \mathrm{H}$, and $\mathrm{O}$ via $\mathrm{OES}$ or a thermodynamic equilibrium calculation, while an insignificant amount of hydrogen peroxide was also found because nitrogen oxides $\left(\mathrm{NO}_{\mathrm{x}}\right)$ formed via a thermal mechanism from the nitrogen and oxygen content in water.

We found that the specific input energy, $S I E=($ plasma discharge power $) \times($ processing time $) /$ (volume of treated wastewater), was the sole parameter that characterized the overall chemical aspects of the process, such as phenol and COD removal efficiencies, solution acidity, and conductivity for fixed initial phenol concentrations. A consistent generation of the arc plasma jet, unaffected by the liquid's properties, was indirectly confirmed by measuring $\mathrm{pH}$ and conductivity during operation.

The overall reaction rate of the phenol degradation was estimated as a constant for the different initial phenol concentrations, indicating a pseudo-first-order reaction. However, the final intermediate of the complete decomposition process was found to be oxalic acid. The conversion of oxalic acid to carbon dioxide and water was the slowest reaction in the decomposition pathway of phenol: phenol $\rightarrow$ catechol and resorcinol $\rightarrow$ benzoquinone $\rightarrow$ oxalic acid $\rightarrow \mathrm{CO}_{2}+\mathrm{H}_{2} \mathrm{O}$. 
This in-liquid arc plasma jet system should perform best when the target application fully utilizes the low $\mathrm{pH}$ feature, a strong UV and high-temperature environment at the same time; water pretreatments such as sewage purification and desalination seem to be the most viable and costeffective applications of this method.

\section{Acknowledgement}

The research reported in this publication was supported by funding from King Abdullah University of Science and Technology (KAUST).

\section{References}

1. X. Zhang and M.S. Cha 2015 J. Phys. D: Appl. Phys. 48215201.

2. P. Lukes, E. Dolezalova, I. Sisrova and M. Clupek 2014 Plasma Sources Sci. Technol. 23015019.

3. B. Jiang, J. T. Zheng, S. Qiu, M. B. Wu, Q. H. Zhang, Z. F. Yan and Q. Zh. Xue 2014 Chem. Eng. J. $236348-368$.

4. P. Bruggeman and C. Leys 2009 J. Phys. D: Appl. Phys. 42053001.

5. P. Bruggeman, M. J. Kushner and B. R. Locke 2016 Plasma Sources Sci. Technol. 25053002.

6. A. Hamdan and M.S. Cha 2016 J. Phys. D: Appl. Phys 49245203.

7. V. V. Kovačević, B. Dojčinović, M. Jović, G. Roglić, B. Obradović and M. Kuraica1 2017 J. Phys. D: Appl. Phys. $\mathbf{5 0} 155205$.

8. J. Gao, Y. J. Liu, W. Yang, L. M. Pu, J. Yu and Q. F. Lu 2003 Plasma Sources Sci. Technol. 12533.

9. H. Wang, J. Li, X. Quan, Y. Wu, G. F. Li and F. Z. Wang 2007 J. Hazard. Mater. 141 336-43.

10. Y. J. Liu and X. Z. Jiang 2005 Environ. Sci. Technol. 39 8512-8517.

11. P. Baroch, N. Saito and O. Takai 2008 J. Phys. D: Appl. Phys. 418.

12. F. Abdelmalek, M. R. Ghezzar, M. Belhadj, A. Addou and J. L. Brisset 2006 Ind. Engineer. Chem. Res. 45 23-29. 
13. C. J. Sidney, M. Sato and R. H. Davis 1987 IEEE Trans. Ind. Appl. 222

14. B. R. Locke and K. Y. Shih 2011 Plasma Sources Sci. Technol. 20034006.

15. B. P. Dojčinović, G. Roglić, B. M. Obradović, M. M. Kuraica, M. M. Kostić, J. Nešić and D. Manojlović 2011 J. Hazard. Mater. 192 763-771.

16. M. Tichonovas, E. Krugly, V. Racys, R. Hippler, V. Kauneliene, I. Stasiulaitiene and D. Martuzevicius 2013 Chem. Engineer. J. 229 9-19

17. J. Z. Gao, Y. J. Liu, Y. Wu, L. Pu, J. Yu and Q. F. Lu 2003 Plasma Sources Sci. Technol. 124533. 18. S. Seiji, M. Hori, S. Rauf, K. Tachibana, P. Bruggeman, G. Kroesen, J. C. Whitehead, A. B. Murphy, A. F. Gutsol, S. Starikovskaia, U. Kortshagen, J. Boeuf, T. J. Sommerer, M. J. Kushner, U. Czarnetzki and N. Mason 2012 J. Phys. D: Appl. Phys. 45253001.

19. Y. S. Mok and J. O. Jo, 2007 Korean J. Chem. Engineer. 24 607-611.

20. J. H. Yan, C. M. Du, X. D. Li, X. D. Sun, M. J. Ni, K. F. Cen and B. Cheron 2005 Plasma Sources Sci. Technol. 144637.

21. G. Qu, D. Liang, D. Qu, Y. Huang, T. Liu, H. Mao, P. Ji, D. Huang 2013 Chem. Engineer. J. 228 28-35.

22. L. Wang and X. Jiang 2009 J. Hazard. Mater. 161 926-32. 